\title{
Physical Self-Motion Facilitates Object Recognition, but does not Enable View-Independence
}

\author{
WataruTeramoto* \\ Max Planck Institute for Biological Cybernetics
}

\section{Introduction}

It is well known that people have difficulties in recognizing an object from novel views as compared to learned views, resulting in increased response times and/or errors. This so-called viewdependency has been confirmed by many studies. In the natural environment, however, there are two ways of changing views of an object: one is to rotate an object in front of a stationary observer (object-movement), the other is for the observer to move around a stationary object (observer-movement). Note that almost all previous studies are based on the former procedure. Simons et al. [2002] criticized previous studies in this regard and examined the difference between object- and observer-movement directly. As a result, Simons et al. [2002] reported the elimination of this view-dependency when novel views resulted from observermovement, instead of object-movement. They suggest the contribution of extra-retinal (vestibular and proprioceptive) information to object recognition. Recently, however, Zhao et al. [2007] reported that the observer's movement from one view to another only decreased view-dependency without fully eliminating it. Furthermore, even this effect vanished for rotations of $90^{\circ}$ instead of $50^{\circ}$. Larger rotations were not tested. The aim of the present study was to clarify the underlying mechanism of this phenomenon and to investigate larger angles of view change $\left(45-180^{\circ}\right.$, in $45^{\circ}$ steps $)$.

\section{Experiments and Results}

Two experiments were conducted using an eMagin Z800 3D Visor head-mounted display that was tracked by 16 Vicon MX 13 motion capture cameras. An upright cylinder with viewing windows was located on a round table in the virtual world. All target objects were presented inside the cylinder. Two movement conditions were compared with each other - object-movement and observer-movement. Both experiments consisted of learning, movement and test phases. In the learning phase, the window opened for a short period of time and observers learned an object inside. In the movement phase, the observer moved to the next window on the observer-movement condition. For the object-movement condition, the object was either rotated or replaced by a different object. In the test phase, the window opened again and observers were asked to judge whether or not the object inside was the same as the learned object (sequential same/different task). Five novel objects and five mirrorreversed versions of these objects were created by smoothing the edges of Shepard-Metzler's objects. A mirror-reflected version of the learned object was used as a distractor in Experiment $1(N=13)$, whereas one of the other (i.e., not mirror-reversed) objects was randomly selected on each trial as a distractor in Experiment $2(N=15)$.

\footnotetext{
*e-mail:wataru.teramoto@tuebingen.mpg.de

†e-mail:bernhard.riecke@tuebingen.mpg.de
}

Copyright $\odot 2007$ by the Association for Computing Machinery, Inc.

Permission to make digital or hard copies of part or all of this work for personal or classroom use is granted without fee provided that copies are not made or distributed for commercial advantage and that copies bear this notice and the full citation on the first page. Copyrights for components of this work owned by others than ACM must be honored. Abstracting with credit is permitted. To copy otherwise, to republish, to post on servers, or to redistribute to lists, requires prior specific permission and/or a fee. Request permissions from Permissions Dept, ACM Inc., fax +1 (212) $869-0481$ or e-mail permissions@acm.org.

APGV 2007, Tübingen, Germany, July 26-27, 2007.

(C) 2007 ACM 978-1-59593-670-7/07/0007 $\$ 5.00$

\author{
Bernhard E. Riecke ${ }^{\dagger}$ \\ Max Planck Institute for Biological Cybernetics
}

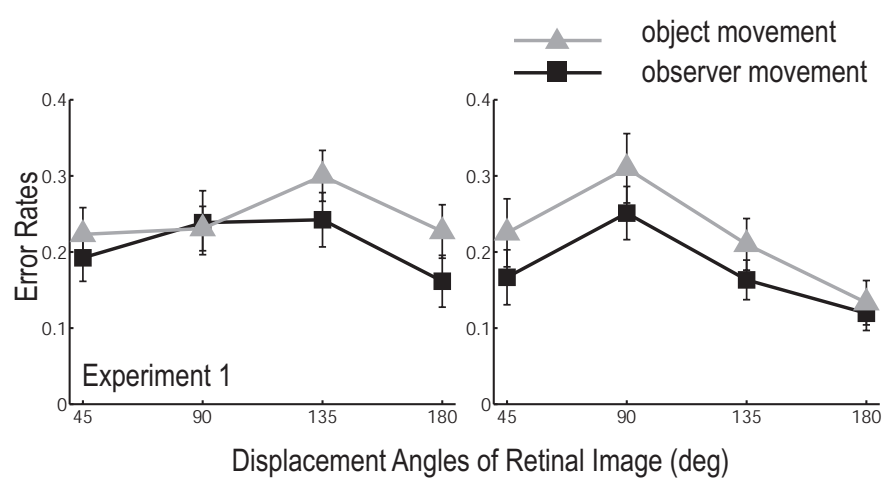

Figure 1: Error rates across all observers in both experiments.

We found almost the same results in both experiments. Errors initially increased as a function of view change, reached a maximum around $135^{\circ}$ in Experiment $1\left(F_{3,36}=4.42, p<.01\right)$ and $90^{\circ}$ in Experiment $2\left(F_{3,42}=8.14, p<.001\right)$, and began to drop when approaching the rear view $\left(180^{\circ}\right)$ of the objects. This relationship was also found in the difficulty ratings in both experiments and in the reaction times in Experiment $1\left(F_{3,36}=7.14, p<.001\right)$, but not in Experiment $2\left(F_{3,42}=1.75\right.$, n.s. $)$. Together, this indicates viewdependency. The pattern of errors for the two movement conditions was, however, clearly different, with the observer-movement condition producing fewer errors across all angles than the objectmovement condition in both experiments $\left(F_{1,12}=7.96, p<.02\right.$ in Experiment $1, F_{1,14}=3.88, p<.07$ in Experiment 2 ). No interaction between movement conditions and angles of view change was found for any of the dependent variables. This suggests a similar advantage of observer movements, independent of the angles of view change.

\section{Conclusion}

Both experiments showed a significant overall advantage of viewer movements over object movements. Note, however, that performance was still viewpoint-dependent. These results suggest an involvement of partially advantageous and cost-effective transformation mechanisms, but not a complete automatic spatial-updating mechanism as proposed by Simons et al. [2002], when observers move.

\section{References}

Simons, D. J., WAng, R. F., AND RoddenberRy, D. H. 2002. How are three dimensional objects represented in the brain? Perception and Psychophysics 64, 4, 521-530.

Zhao, M., Zhou, G., Mou, W., Hayward, W. G., And OWEN, C. B. 2007. Spatial updating during locomotion does not eliminate viewpoint-dependent visual object processing. $\mathrm{Vi}$ sual Cognition 15, 4, 402-419. 